\title{
Mevlana Kubbe-i Hadra (Konya) Dış Duvarının 1912 ve 1965 Yıllarındaki Onarımlarında Kullanılan Çinilerin Karakterizasyonu
}

\author{
Çetin ÖZTÜRK ${ }^{1}$ \\ ${ }^{1}$ Necmettin Erbakan Üniversitesi, Güzel Sanatlar Fakültesi, Geleneksel Türk Sanatları Bölümü, Konya \\ e-posta: cozturk@erbakan.edu.tr. ORCID ID: http://orcid.org/0000-0001-8697-0929 \\ Geliş Tarihi: 15.03.2020 Kabul Tarihi: 28.10.2020
}

Öz

Anahtar kelimeler Kubbe-i Hadra;

Çini;

Yenileme;

Kütahya;

Karakterizasyon

\begin{abstract}
Birçok medeniyete ev sahipliği yapmış olan Konya şehri, tarihi anıtsal yapıtlar açısından oldukça zengindir. Konya'daki bu yapıtlardan biri olan Mevlana Türbesi dünya kültür mirasının önemli bir parçasıdır. Kubbe-i Hadra olarak da bilinen Mevlana Türbesinin dış cephe duvarlarını süsleyen çiniler asırlar boyu birçok defa bakım ve onarımdan geçmiştir. En son 1965 yılındaki onarımda yenilenen çiniler artık servis ömrünü tamamladığından yenilenmesi gerekmektedir. Mevcut ve önceki dönemlere ait kubbe çinilerinin karakteristik özelliklerinin ortaya çıkarılması yenilenecek olan çinilerin üretim teknolojisinin belirlenmesinde rol oynayabilir. Bu amaçla Mevlana Müze Müdürlüğünden 1912 ve 1965 dönemlerine ait çini örnekleri temin edilmiş ve bu çini örnekleri fiziksel, kimyasal, mineralojik ve mikroyapı özellikleri açısından karakterize edilmiştir. Karakterizasyon çalışmaları sonucu elde edilen bulgulara göre aynı aile tarafından farklı zamanlarda üretildiği tespit edilen çinilerin üretim teknolojileri ve karakteristik özelliklerinin birbirlerinden tamamen farklı olduğu belirlenmiştir.
\end{abstract}

\section{Characterization of Mevlana Green Dome (Konya) Outer Wall Tiles Used in Repairs in 1912 and 1965}

\begin{abstract}
Konya city, which has hosted many civilizations, is rich in monumental historical works. Mevlana Mausoleum, one of these works in Konya, is an essential part of the world cultural heritage. Tiles decorating the exterior walls of the Mevlana Mausoleum, also known as Kubbe-i Hadra, have been maintained and repaired many times over the centuries. Since the tiles, which were last renovated in 1965 , have completed their service life, they need to be renewed today. Uncovering the characteristic features of the dome tiles of current and previous periods may play a role in determining the production technology of the tiles to be renewed. For this purpose, tile samples belonging to the period of 1912 and 1965 were obtained from Mevlana Museum Directorate, and these tile samples were characterized in terms of their physical, chemical, mineralogical and microstructural properties. According to the findings obtained as a result of the characterization studies, it was revealed that the production technologies and characteristics of the tiles, which were found to be produced at different times by the same family, are entirely different from each other.
\end{abstract}

(c) Afyon Kocatepe Üniversitesi

\section{Giriş}

Çini, Türklerde geçmişten günümüze dini ve sivil mimaride duvar kaplama malzemesi olarak sıklıkla tercih edilmektedir. Çiniler, uygulandıkları yapıya dekoratif görsellik katmakla beraber aşınma ve korozyon gibi dış etkilere karşı da yapının dayanımını arttırırlar (Bayazit ve Işık 2014). Çevresel faktörler, çini malzemenin üretiminden kaynaklı etkenler ve çini uygulama çalışmalarında yanlış malzeme seçimi gibi nedenlerden dolayı çinilerde zaman içerisinde bozulma veya tahribatlar meydana gelir. Tahrip olan yapıda bakım ve onarım işlemine başlanmadan önce çinili yapıdaki mevcut korunma durumları, çinilerdeki bozulmalar ve bozulmalara sebep olan etkenler tespit edilmelidir. Yapının özgünlüğü korunacak şekilde uygun bir onarım yöntemi belirlendikten sonra çinilerde yenileme işlemi yapılmalıdır. 
Konya'daki tarihi yapılardan olan ve halk arasında Kubbe-i Hadra olarak da bilinen Mevlana Türbesinin gövde ve külah dış cephe duvarlarını kaplayan çiniler son olarak 1965 yılında gerçekleştirilen onarımda yenilenmiştir. (Bakırcı 2019). Günümüzde servis ömrünü tamamlayan bu çinilerin yenilenmesi zaruridir. Türbe, 1274 yılında fil ayağı olarak tabir edilen dört adet kalın sütun üzerine inşa edilmiştir (Özönder 1988). İnşa sonrası dış cephe duvarı çini ile kaplanan kubbenin iç kısmının da çini ve kalemişi süslemelerle kaplanmış olduğu söylense de iç mekândaki çiniler günümüzde mevcut değildir (Baysal 2020: 10). Kubbeyi süsleyen çiniler geçmişten bu yana birçok kez aslına uygun bir biçimde bakım ve onarım işlemlerinden geçirilerek yenilenmiştir (Baysal ve Sayın 2019). Tarihi kayıtlardan 1698 yılında kubbe duvarlarına kaplanan çinilerin İznik'te (Oğuzoğlu ve Mülayim 1984), 1817 yılı ve sonrasında kaplanan çinilerin ise Kütahya'da imal edildiği (Küçükdağ 1996) anlaşılmaktadır.

Bugünkü çiniler, 1965 yılında tamamlanan onarımda kubbeye kaplanmış ve Kütahya'da Metin Çini Fabrikası tarafından imal edilmiştir (Önge 1987, Bakırcı 2007). Metin Çini Fabrikasının o dönemki sahibi olan Edip Çinicioğlu, Kubbe-i Hadra'nın 1912 yılındaki onarımında kullanılan çinilerin imalatçısı olan Hafız Hacl Mehmet Emin Efendinin de torunudur (Arlı 1989: 10-16). Mehmet Emin Usta Cumhuriyet öncesi dönem Kütahya çiniciliğinin Cumhuriyet dönemine geçişini sağlayan, Kütahya' daki ilk yerli çini fabrikasının sahibidir. 1899 yılında işletmeye başladığı fabrikayı vefatından sonra (1922) oğlu Hakkı Çinicioğlu işletmiştir (Şahin 1988). 1942'de "Metin Çini" ismiyle üretimine devam eden fabrikaya 1949 yılından sonra Hakkı Çinicioğlu' nun oğulları Vedat ve Edip Çinicioğlu da ortak olarak dâhil olmuştur. Fabrika 2002 yılına kadar varlığını sürdürdükten sonra kapanmıştır (Çini 2002:58-61). Bu bilgilerden, 1912 ve 1965 yıllarında Kubbe-i Hadra onarımlarında kullanılan çinilerin aynı ailenin farklı kuşakları tarafından Kütahya'da üretildiği anlaşımaktadır.

Tarihi süreçte Kütahya'da eskiden beri çini üretildiği bilinmekteyse de Kütahya çiniciliği kendini 17. yy'da İznik çiniciliğinin bitmesiyle göstermiş ve 18.yy.'da çini üretim merkezi haline gelmiştir. 19.yy. başlarından itibaren duraklayan Kütahya çiniciliği aynı yüzyılın sonlarına doğru oldukça gerilemiştir. 20.yy. başlarında ise I. Ulusal Mimarlık Dönemi'nin etkisiyle çinicilikte canlanma görülmüş ve Kütahya çiniciliği teknolojik açıdan gelişim göstermiştir. Bu dönemdeki Kütahya çini bünyelerinin yüksek oranda kuvars ve bağlayıcı kilden oluştuğu bilinmektedir (Arlı 1989 ve Şahin 1988). Cumhuriyet sonrası Kütahya çiniciliğinde bünyedeki kil oranı giderek artmış ve bünye reçetesi Kundukviran kaolini, Kundukviran kumu, maya (Kütahya'da Halk arasında "baş kili" olarak da bilinen beyaz pişme renkli bentonit kil) (Kızıl 2010:9) ve kuvars şeklinde değişmiştir. 1935 yılında Dümbüldek toprağının çini imalatında kullanılmaya başlanmasıyla çini hamur reçetesi; Dümbüldek toprağı 50, Tebeşir 15 , Maya 25, Kuvars 15, Mihaliçcık kili 5 birimden oluşmuştur. Bu reçete 1980 'lere kadar kullanılmıştır. Cumhuriyet dönemi öncesi ve Cumhuriyet döneminde Kütahya çiniciliğinde sır reçetesi uzun yıllar hiç değişmeden devam etmiştir. Bu sır reçetesinde; Kuvars 20, Sülyen 20, Cam 5 ve Soda 7 birim olup sır beyaz, şeffaf ve parlak görünümdedir (Şahin 1988). Yüzyıl içerisinde kuvars ağılıklı bünyeden kil ağırlıklı bünyeye değişen Kütahya çiniciliğinde kil ve kuvarsın yanı sıra kullanılan diğer hammaddeler, kaolen, dolomit ve kalsittir (Gülaçtı 2012). Kütahyalı çiniciler Cumhuriyet dönemi sonrasında (özellikle 1960 sonrası dönem) İtalya ve Almanya'dan teknoloji ve ekipman transferi yapmış ve bu ülkelerden gelen seramik ustaları ile Ar-Ge çalışmalarında bulunmuşlardır (Şahin 1988). Kütahya'da 1978 yılından bu yana geleneksel Kütahya çini üreticisi olan Çinikop A.Ş.'den (Çini, 1991: 21 ) alınan Kütahya çini bünyesinin kimyasal analizinde oksitlerin ağırlıkça \%'de oranı; $\mathrm{SiO}_{2}$ : 66.97, $\mathrm{Al}_{2} \mathrm{O}_{3}$ : 12.72, $\mathrm{Fe}_{2} \mathrm{O}_{3}: 0.49, \mathrm{TiO}_{2}: 0.45, \mathrm{CaO}: 0.55, \mathrm{MgO}: 5.63$, $\mathrm{Na}_{2} \mathrm{O}: 0.33, K_{2} \mathrm{O}: 0.80$, Ateş Kaybı: 11.50'dir. Kurşunlu sırın kimyasal analizinde ise oksitlerin ağılıkça \%'de oranı; $\mathrm{SiO}_{2}: 42.73, \mathrm{Al}_{2} \mathrm{O}_{3}: 0.17, \mathrm{Fe}_{2} \mathrm{O}_{3}$ : 0.10, $\mathrm{CaO}: 0.61, \mathrm{MgO}: 0.30, \mathrm{Na}_{2} \mathrm{O}: 7.03, \mathrm{~K}_{2} \mathrm{O}: 0.03$, $\mathrm{PbO}: 38.28, \mathrm{~B}_{2} \mathrm{O}_{5}: 2.77$ ve çininin su emme oranı \%27'dir. Coşkun vd. (2015) tarafından yapılan çalışmada günümüz Kütahya yüksek poroziteli beyaz pişen çini bünyesinin kuvars, kristobalit ve feldspat minerallerinden oluştuğu, kuvarsın ise ana mineral olduğu belirlenmiştir. 
Kütahya çinilerinin kendi içinde dönemsel olarak farklılıklar göstermesi İznik çinileri gibi karakterize edilmesini zorlaştırsa da İznik ile Kütahya çiniciliği bariz farklılıklar göstermektedir. Örneğin İznik çiniciliğinde bünyede kullanılan kuvars yüksek orandayken, Kütahya çiniciliğinde daha düşüktür. İznik çinilerinin pişirme sıcaklığı Kütahya çinilerininkinden daha düşüktür (Yılmaz 2011). İznik çiniciliğinde kurşun sırçalı (fritli) hamur kullanılırken Kütahya'da kireç-alkali hamur kullanılmıştır (Kahraman 2018).

1965 yılı onarımında yenilenen Kubbe-i Hadra çini kaplamaları servis ömrünü tamamlamış olup yenilenmesi için Konya Valiliği ve Konya II Kültür ve Turizm Müdürlüğü tarafından 01.06.2020 tarihinde Bilim Kurulu oluşturulmuştur. Kurul, kubbe çinilerinin geleneksel tarzda ve turkuaz renkte kalaylı sırlı imal ettirilmesine karar vermiştir. Geleneksel tarz yüksek silisli bünye ve 'Tap Tap' şekillendirme yöntemini ifade etmektedir (Kubbe-i Hadra Bilim Kurulu Kararları, 2020).

Bu çalışmada Konya Müze Müdürlüğünden temin edilen 1912 ve 1965 yılı onarımlarında kullanılan dış duvar çinilerinin bünye ve sır yapıları karakterize edilmiştir. Karakterizasyon sonucu elde edilen veriler hem birbirleriyle hem de günümüz Kütahya ve İznik çinileriyle karşılaştırılmış, aralarındaki benzerlik ve farklılıklar ortaya konulmuştur.

Çalışma sonuçlarının 15 Haziran 2020 - 01 Aralık 2021 tarihlerinde yenilenmesi planlanan (Int Kyn. 1) Kubbe-i Hadra çinilerinin üretim teknolojisinin belirlenmesinde etkin bir rol oynayabileceği düşünülmektedir.

\section{Materyal ve Metot}

Günümüz Kubbe-i Hadra dış duvarlarını süsleyen çinilerin ve daha önceki dönemlerde kullanılmış çinilerin karakteristik özelliklerinin incelenip araştırılması yenilenecek olan çinilerin üretim teknolojisinin belirlenmesinde rol oynayabilir. Bu amaçla Konya Müze Müdürlüğünden kubbede kullanılmış olan çini örnekleri istenmiş ve 1912 ve 1965 dönemlerine ait olduğu belirtilen çini örnekleri temin edilmiştir. Çalışmada ilk olarak Kubbe-i Hadra'da yerinde inceleme ve fotoğraflama yapılmış, sonrasında Konya Müze Müdürlüğünden temin edilen çinilerin su emme (\%), görünür porozite (\%) ve yığınsal yoğunluk $\left(\mathrm{g} / \mathrm{cm}^{3}\right)$ değerleri Arşimed yöntemine göre ölçülmüştür. Karakterizasyon çalışmaları kapsamında XRF (Xışınları floresans), XRD (X-ışınları kııınımı) ve SEM (tarama elektron mikroskobu) analizleri gerçekleştirilmiştir. Çinilerin kimyasal bileşimleri Rigaku marka ZSX Primus II model XRF cihazı ile belirlenmiştir. Çinilerin mikroyapı görüntüleri HITACHI SU 1510, (Japonya) kullanılarak elde edilmiştir. Çini örneklerinin mikroyapısal analizi SEM cihazında sekonder elektron görüntülemesi ile gözlemlenmiştir. XRF kimyasal analizi ve SEM Mikroyapı analizi Necmettin Erbakan Üniversitesi Bilim ve Teknoloji Araştırma ve Uygulama Merkezinde (BITAM) yapılmıştır. Çinilerin yapılarındaki mineralleri belirlemek için Bruker marka D8 Advance model cihazda $2 \theta$ tarama açısı 5$70^{\circ}$ arasında olacak şekilde XRD analizi gerçekleştirilmiştir. Analizlerde $\mathrm{Cu} \mathrm{K} \alpha=1,54 \mathrm{~A}^{\circ}$ dalga boyuna sahip $\mathrm{X}$-ışını kullanılmış ve 3 derece/dakika tarama hız ile taranmıştır. XRD analizi Afyon Kocatepe Üniversitesi Teknoloji Uygulama ve Araştırma Merkezinde (TUAM) gerçekleştirilmiştir.

\section{Bulgular}

Kubbe-i Hadra çinilerindeki tahribatlar yerinde incelenerek tespit edilmiştir. Bu tahribatlar; kubbe tabanında enine ve dikine derin çatlaklar, yer yer kabarmalar, kubbenin uç kısmına doğru kavlama, kopma ve dökülmeler şeklindedir. Şekil 1 (a), (b) ve (c)'de çinilerdeki tahribatlardan örnekler görülmektedir. (a)

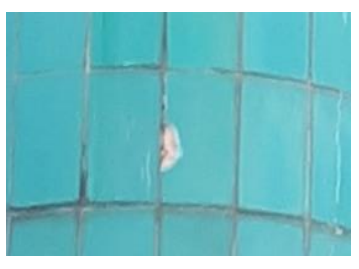

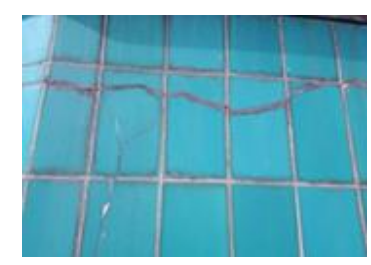

(b)

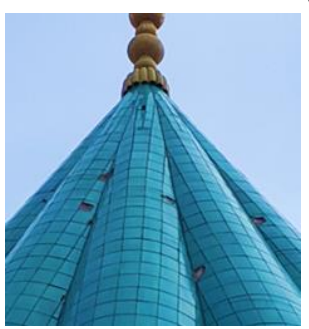

(c) 
Şekil 1. Şekil 1. (a), (b), (c) Günümüz Kubbe-i Hadra gövde ve külah kısımdaki dış cephe çinilerinde atmosferik etkilerle zamanla oluşan tahribat.

Şekil 2 (a) 'da ise derz dolgusundaki boşalma ve Şekil 2 (b)' de de derz dolgu aralığından sökülen çini plaka altındaki çimentolu yapı görülmektedir. Şekil 2 (a) ve (b)'den çinilerdeki tahribat nedenleri arasında yanlış malzeme kullanımının da olduğu anlaşılmaktadır. Çünkü çinilerin dış cephe kaplamalarında bağlayıcı olarak çimento kullanımı zamanla tuz oluşumuna neden olmakta ve oluşan tuz nem ve Isı etkisiyle kristalleşerek çinide çatlamalar ve sırda dökülmelere yol açmaktadır (Işıkhan 2012).

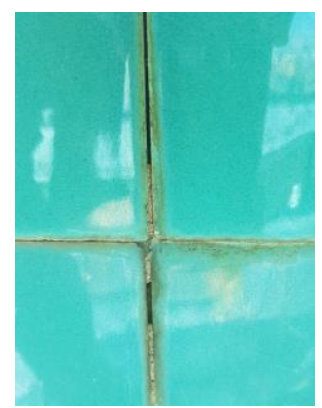

Şekil 2 (a). Günümüz Kubbe-i Hadra Gövde Çinileri arasındaki derz dolgularında oluşan dökülme ve derzlerde çözülme.

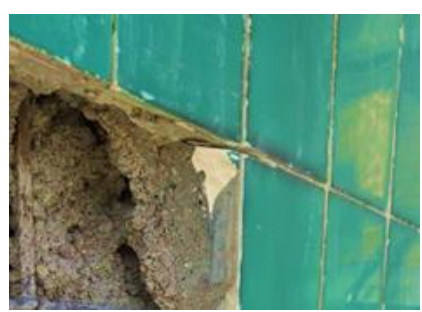

Şekil 2(b). Tahrip olmuş derz dolgusundan sökülen çini plaka altındaki çimento harcın görünümü

Çinilerdeki meydana gelen tahribatta hatalı malzeme seçimi ve ağır iklim şartları önemli rol oynamaktadır. Özellikle kışın meydana gelen donma ve çözülme olayları duvar kaplama malzemelerinin emme, basınç ve aşınma dayanımlarını olumsuz etkilemektedir. Bu yüzden Kubbe-i Hadra gibi tarihi yapıtların dış cephe kaplama malzemeleri yenilenirken, üretilecek olan kaplama malzemesinden beklenen teknik özelliklerin belirlenmesinde o bölgenin iklim şartlarına göre hazırlanmış 'Ayrışma indeksi' olarak adlandırılan verilerden faydalanılmalıdır. İskender ışık ve arkadaşları tarafından hazırlanan Türkiye'nin ayrışma indeksi haritasında Konya donma/çözülme olaylarının sert görüldüğü bölgede yer almaktadır (Işık ve ark.2017).
Konya Müze Müdürlüğünden temin edilen 1912 ve 1965 yıllarındaki onarıma ait çinilerden temsili örnekler Şekil 3'te verilmiştir.

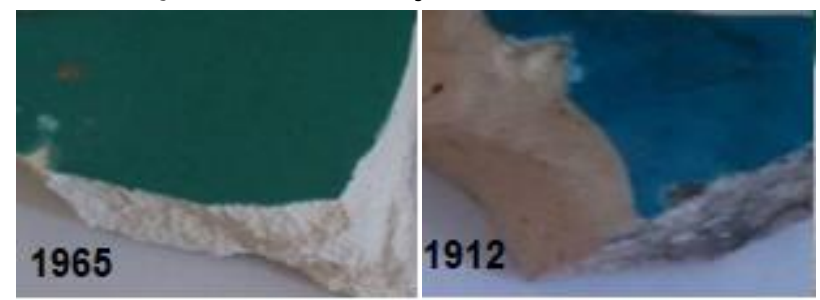

Şekil 3. (a)1965 yılı kubbe çinisi, (b)1912 yılı kubbe çinisi

Şekil 3’e göre 1965 yılı çini bünyesinin beyaz renkli, yüzeyinin maviye çalan yeşil renkte örtücü sırlı, 1912 yılı çini bünyesinin ise sarımtırak, sırının ise turkuaz renkte olduğu görülmektedir.

\subsection{Fiziksel Analiz Sonuçları}

Çini örneklerine yapılan fiziksel test sonuçları Çizelge 1 'de verilmiştir.

Çizelge 1. 1965 ve 1912 yıllarına ait türbe çinilerinin fiziksel özellikleri.

\begin{tabular}{lcc}
\hline Fiziksel testler & 1965 Yılı Çinisi & $\mathbf{1 9 1 2}$ Yılı Çinisi \\
\hline Su emme (\%) & 16,68 & 22,29 \\
\hline Yığınsal yoğunluk g/cm $\left.{ }^{3}\right)$ & 1,96 & 1,64 \\
\hline Görünür porozite (\%) & 32,94 & 36,56 \\
\hline
\end{tabular}

Çizelge 1'den 1965 yılı çinisinin 1912 yılı çinisine göre daha yoğun, su emme ve porozitesinin ise daha düşük olduğu anlaşılmaktadır.

\subsection{Kimyasal Analiz Sonuçları}

Şekil 4 ve 5 'te çinilerin bünye ve sırlarının kimyasal analiz sonuçları verilmiştir.

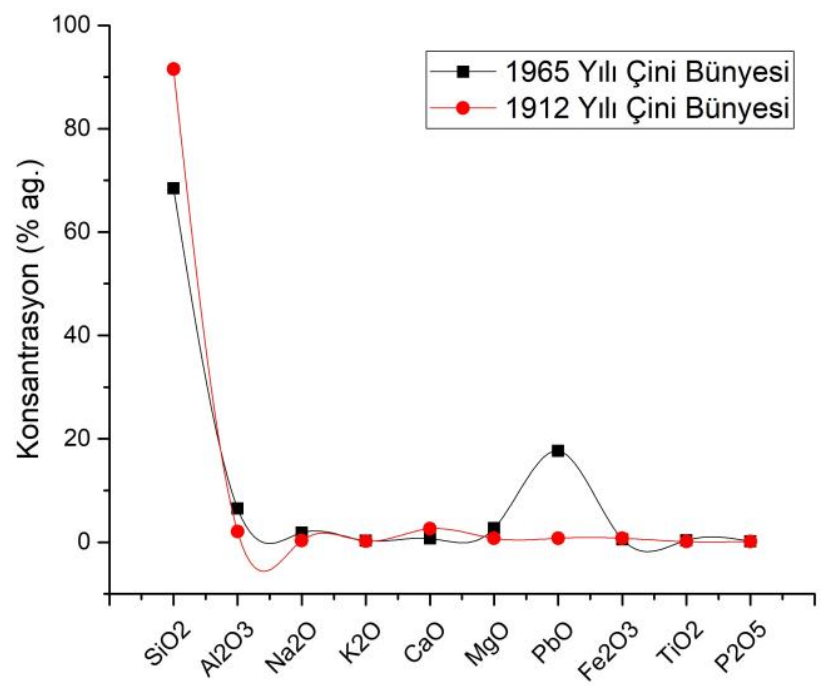

Şekil 4. 1912 ve 1965 yılı çini bünyelerinin kimyasal kompozisyonu 
Şekil 4'e göre 1912 yılı çini bünyesi yüksek silika içeriğinden dolayı (\% 91,54) İznik ve I. Ulusal Mimarlık Dönemi Kütahya çinileri ile uyumludur. İznik ve I. Ulusal Mimarlık Dönemi Kütahya çini bünyelerinin yüksek silika içerdiği literatürde (Okyar 2005, Kahraman 2018) belirtilmektedir. Bu yönüyle 1912 yılındaki onarımda kullanılan çini bünyesi bileşim olarak taş çini özelliği taşımaktadır. 1965 yılı çini örneğindeki bünyenin silika içeriği $(\% 68,45)$ Kütahya çiniciliğinde Cumhuriyet sonrası bazı dönemlerdeki bünye bileşimleri ile uyumlu olsa da bünyede yüksek kurşun oksit içeriği $(\% 17,64)$ gerek Kütahya gerekse İznik çiniciliğinde hiç bir dönem görülmemiştir. 1912 ve 1965 yılı çinilerinin toplam alkali, toprak alkali ve alümina değerleri ise literatürde (Atagün 2010, Kahraman 2018, Okyar 2005) benzer konuda yapılmış araştırma sonuçları ile uyumludur.

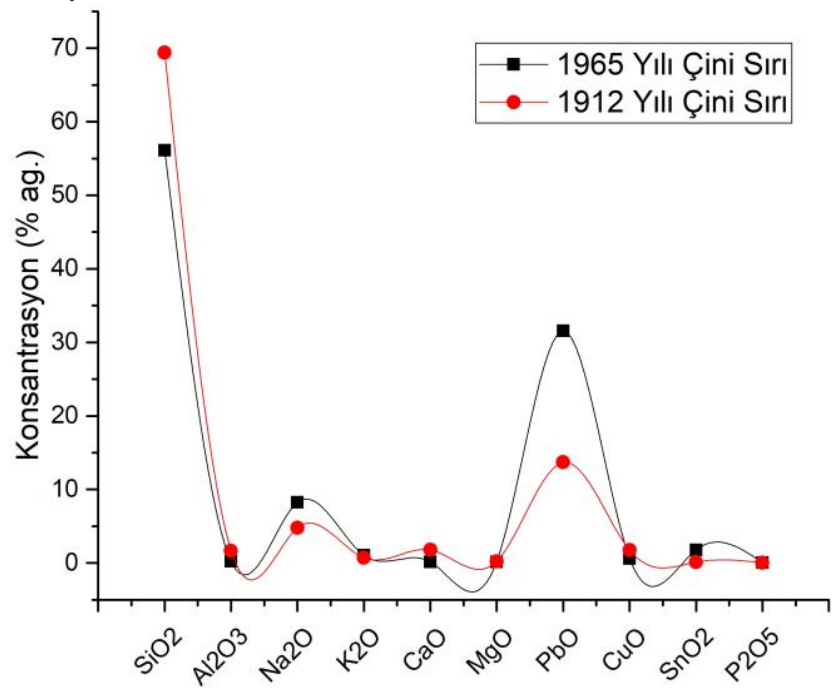

Şekil 5. 1912 ve 1965 yılı çini sırlarının kimyasal kompozisyonu

Şekil 5'te 1912 ve 1965 yılı çinilerinin sır bileşimleri verilmiştir. Analiz sonuçları her iki dönemde de renklendirici olarak farklı oranlarda bakır oksit kullanıldığını göstermektedir.

1965 yılı çini sırındaki örtücülük nispeten yüksek kalay oksit $(\% 1,78)$ içeriğinden kaynaklanmaktadır. Şekil 5'te görüldüğü üzere iki dönem sır bileşimleri arasındaki en bariz fark 1965 yılı çini sırındaki yüksek kurşun oksit (PbO: \% 31,55) içeriğidir. Maviye çalan yeşil renk oluşumunda yüksek orandaki $\mathrm{PbO}$ 'nun $\mathrm{CuO}$ ile yaptığı bileşikten kaynaklandığı düşünülmektedir.

\subsection{X-Işınları Kırınımı (XRD) Analizi Sonuçları}

Şekil 6'da çini bünyelerinin XRD analiz grafiği verilmiştir.

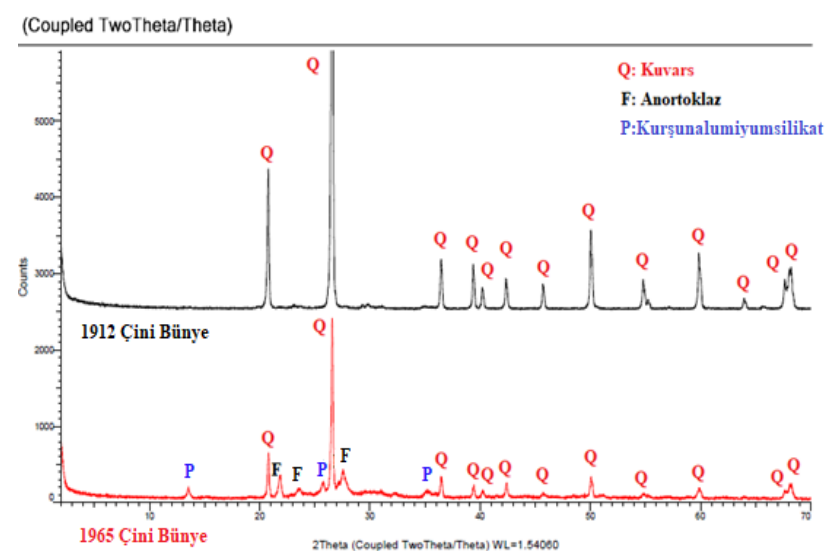

Şekil 6. Farklı dönem çini bünyelerinin X-ışınları kııınımı (XRD) analiz sonuçları.

Şekil 6'ya göre 1912 yılı çini örneğinde belirgin biçimde sadece kuvars fazı görülürken, 1965 yılına ait çinide kuvars $\left(\mathrm{SiO}_{2}\right)$, anortoklaz (( $\left.\left.\mathrm{Na}_{0.63} \mathrm{~K}_{0.27} \mathrm{Ca}_{0.1}\right)\left(\mathrm{Al}_{1.1} \mathrm{Si}_{2.9} \mathrm{O}_{8}\right)\right)$ ve kurşunalumiyumsilikat $\left(\mathrm{PbAl}_{2} \mathrm{Si}_{2} \mathrm{O}_{8}\right)$ fazları görülmektedir. Kuvars, İznik ve Kütahya çinilerinde görülen başlıca mineraldir. Bunun dışında bu çinilerde feldspat, plajioklas, mika, kalsit, vollastonit, jibs, epidot, serizit, klorit ve rutil türü minerallere de rastlanıldığı literatürde (Okyar 1996) belirtilmektedir. Anortoklaz; bünyesinde sodyum, alüminyum ve silikatın olduğu alkali feldspattır (Keskin 1998). Dolayısıyla İznik ve Kütahya çini bünyelerinde olması muhtemeldir. Kurşunalumiyumsilikat fazı ise yüksek orandaki kurşun içeriğinden gelişen bir mineraldir. Ergitici özellikteki kurşun, bünyenin pişirim sıcaklığını düşürmekte, alümina ise yükseltmektedir. Yapılan literatür incelemelerinde Türk çiniciliğinde böyle bir mineral ile karşılaşılmamıştır.

Şekil 7'de farklı dönem çini sırlarının X-ışınları kırınımı analiz sonuçları verilmiştir.

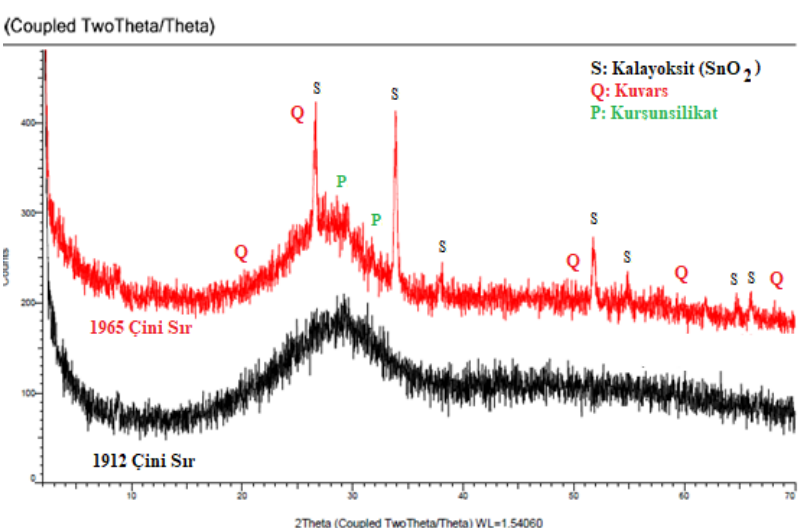


Şekil 7. Farklı dönem çini sırlarının X-ışınları kırınımı (XRD) analiz sonuçları.

Şekil 7'de 1912 ve 1965 yılı çini sırlarında kuvars $\left(\mathrm{SiO}_{2}\right)$ ve kurşunsilikat $\left(\mathrm{Pb}_{5} \mathrm{SiO}_{7}\right)^{\prime}$ a ait kristalin fazlar bulunmaktadır. Ayrıca 1965 yılı çini sırında kalay oksite $\left(\mathrm{SnO}_{2}\right)$ ait pikler görülmektedir. Kalay oksitin İznik çini sır bileşimlerinde yer alan bir faz olduğu literatürde (Sevgili 2006) belirtilmektedir.

\subsection{SEM Mikroyapı Analiz Sonuçları}

Şekil 8 ve 9'da çini örneklerinin SEM görüntüleri verilmiştir.

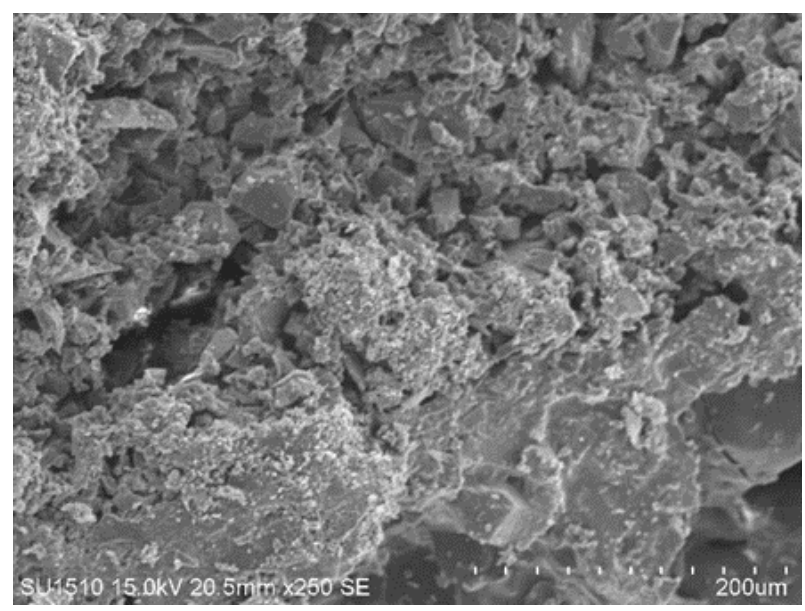

Şekil 8. 1912 yılı çini bünyesinin SEM görüntüsü

1912 yılı çini bünyesinin Şekil 8'de verilen SEM görüntüsüne göre bünye yapısı gözenekli ve gözenek boyutu irili ufaklıdır. Bu çininin geleneksel şekillendirme yöntemlerinden olan 'Tap Tap' yöntemi ile şekillendirildiğini göstermektedir. Osmanlıdan günümüze yüksek kuvars içerikli çinilerin şekillendirilmesinde kullanılan Tap Tap yönteminde istenilen ebatlarda yapılmış ahşap çerçeve üzerine, bez konularak hazırlanan masse, çerçeve içine elle bastırılarak doldurulur. Sonra üzeri çeşitli aletlerle düzeltilir. Kurumaya başladığında ise ham bünye ters düz edilerek bez alınır ve ham bünyenin kuruma süreci devam ettirilir. (Kızıl 2010:15). Tap tap şekillendirme yöntemi bünyede su tahliyesini kolaylaştıracak bir gözenek dağılımına imkân sağlamaktadır.

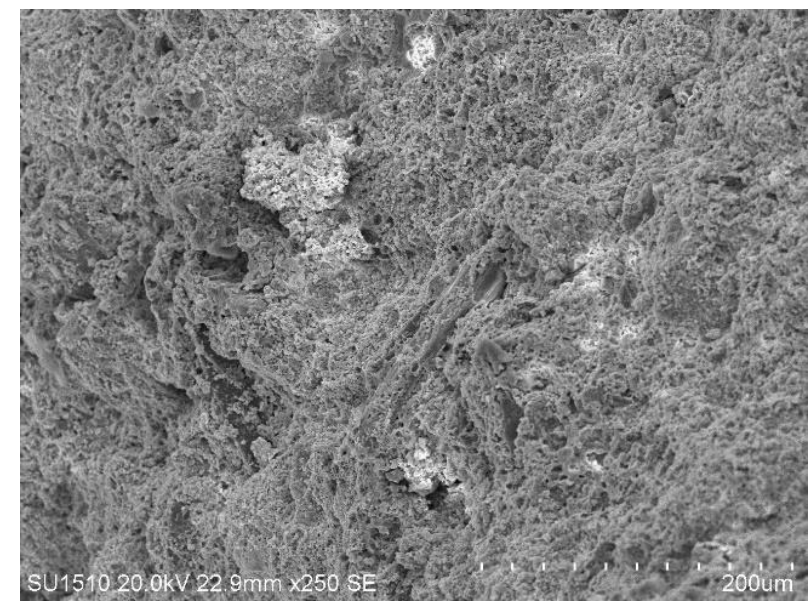

Şekil 9. 1965 yılı çini bünyesinin SEM görüntüsü.

Şekil 9'da verilen 1965 yılı çinisinin SEM görüntüsünden ise bünyenin sık dokulu olduğu anlaşılmaktadır. Bununla birlikte bünyede levha şeklinde katmanların varlığı çinilerin presleme yöntemi ile şekillendirildiğini göstermektedir. Sık doku killi bünyelerde mukavemeti arttırsa da bünyenin su tahliyesini zorlaştırdığından atmosferik olaylar sebebiyle zamanla çinide tahribata yol açmaktadır.

\section{Tartışma ve Sonuç}

1912 ve 1965 dönemi Mevlana kubbe çinileri aynı aile tarafından (dede ve torunu) imal edilmiştir. Çiniler fiziksel özellikleri açısından karşılaştırıldığında bünye ve sır renklerinin birbirinden farklı olduğu tespit edilmiştir.

1912 yılında kaplanan çini bünyesi gözenekli yapıdadır, 1965 yılında kaplanan çini bünyesi ise sık dokuludur. 1912 yılında kaplanan çiniler geleneksel şekillendirme yöntemi olan Tap Tap yöntemiyle, 1965 yılında kaplanan çiniler ise preste şekillendirme yöntemiyle şekillendirilmiştir.

Türk çiniciliğinin hiçbir döneminde bünyede yüksek oranda kurşun oksit kullanılmamıştır. 1965 yılı çini bünyesinde tespit edilen yüksek orandaki kurşun oksit (\% 17,64) bu açıdan Türk çiniciliğinden ayrılmaktadır.

1965 yılı çini sırındaki yüzey örtücülüğü, bileşimdeki kalayoksit içeriğinden kaynaklanmaktadır. 
Mineralojik açıdan 1912 yılı çinisinde kuvars fazı, 1965 yılı çinisinde ise kuvars, anortoklaz ve kuşunalumiyumsilikat fazları görülmektedir.

Sonuç olarak; çalışmada gerçekleştirilen fiziksel, kimyasal, mineralojik ve mikroyapısal analizlerden 1912 yılı çini örneğinin bünye ve sır yapısının geleneksel Kütahya çinileriyle benzerlikler gösterdiği, 1965 yılı çini örneğinin bünye ve sır yapısının ise Kütahya ve İznik çinilerine benzemediği belirlenmiştir. Söz konusu çininin Ar-Ge çalışmaları ve teknoloji transferi yapmak için o dönem İtalya ve Almanya'dan Kütahya'ya gelen seramikçilerle bağlantılı olabileceği düşünülmektedir.

\section{5. Öneriler}

Ayrışma indeksi haritasında Konya, donma/çözülme olaylarının sert görüldüğü bölgede yer aldığından uzun servis ömrü için kubbe dış cephesine kaplanacak çinilerin seçiminde donma/çözünme testleri de kullanılmalıdır. Bununla birlikte çinilerin duvara montajında kullanılacak hidrolik harç seçiminin de servis ömrünü belirlediği unutulmamalıdır.

\section{Kaynaklar}

Arlı. H. 1989, Kütahyalı Mehmed Emin ve Eserlerinin Üslubu, Yüksek Lisans Tezi, İstanbul Üniversitesi Sosyal Bilimler Enstitüsü, İstanbul, 190.

Atagün D., 2010, Türk Çini Sanatında Renkli Sır Teknikleri ve Reçeteleri, Yüksek Lisans Tezi, Sakarya Üniversitesi, Sosyal Bilimler Enstitüsü, Geleneksel Türk El Sanatları, Sakarya, 87.

Bakırcı N., 2007, Konya Mevlâna Dergâhı, Necmettin Erbakan Üniversitesi Ahmet Keleşoğlu ilahiyat Fakültesi İslam Tarihi ve Sanatları Bölümü Dergisi, 10, 191-202.

Bakırcı N., 2019, Mevlâna Müzesi Kubbe-i Hadrâ'nın Kalem İşi Süslemeleri ve Yapılan Restorasyon Çalışmaları, Selçuk Üniversitesi Sosyal Bilimler Enstitüsü Dergisi, (Prof. Dr. Fuat Sezgin Özel Sayısı), 322-338.
Bayazit M. ve Işık i., 2014, Mimaride Kullanılan Çinilerin Bozunma ve Aşınma Davranışları, Afyon Kocatepe Üniversitesi Fen ve Mühendislik Bilimleri Dergisi, OZ5724, 153-158.

Baysal A. F., 2020, Kubbe-i Hadrâ Kalemişi Tezyinatı ve Yenilenmesi. Konya: Palet Yayınları, 100-10.

Baysal, A.F. ve Sayın., A.Z, 2019, Restorasyon Sonrası Kubbe-i Hadrâ Kalem İşleri Üzerine Bir Değerlendirme, Necmettin Erbakan Üniversitesi Ahmet Keleşoğlu ilahiyat Fakültesi Islam Tarihi ve Sanatları Bölümü Dergisi, 33, 39-64.

Coşkun N. D., Işık E., Şahin A. S., Börekçioğlu Ç. ve Uz V., 2015, Yüksek Poroziteli Beyaz Pişen Seramik Çamurunun Karakterizasyonu, Afyon Kocatepe Üniversitesi Fen ve Mühendislik Bilimleri Dergisi, 037103, 14-20.

Çini R., 2002, Ateşin Yarattığı Sanat Kütahya Çiniciliği, Celsus Yayınları, 348-61-58.

Çini, R., 1991, Türk Çiniciliğinde Kütahya, Uycan Yayınları, istanbul, 114-21.

Gülaçtı N., 2012, Seramik Ve Çini Sektöründe Faaliyet Gösteren İşletmelerin Karşılaştıkları Sorunlar Ve Beklentileri, Dumlupınar Üniversitesi Sosyal Bilimler Dergisi, 32, 143-158.

Işık i., Uzunoğlu Aydoğan D. ve Karaca M., 2017, Tarihi yapıların korunması ve güçlendirilmesinde ayrışma indeksi haritasının kullanımı, Uluslararası Katılımlı 6. Tarihi Yapıların Korunması ve Güçlendirilmesi Sempozyumu, 659 - 668. Trabzon: Karadeniz Teknik Üniversitesi.

Işıkhan, S. S., 2012, Tarihi Çinilerde Yapısal Özellikler Ve Karşılaşılan Bozulmalar, Yedi, Dokuz Eylül Üniversitesi Güzel Sanatlar Fakültesi Dergisi, 7, 15-22.

Kahraman G., 2018, 1950' den İtibaren Kütahya Çini Tabaklarının Tasarım Tipolojisi, Yüksek Lisans Tezi, Selçuk Üniversitesi Sosyal Bilimler Enstitüsü, Konya, 256.

Kızıl, M., 2010, Cumhuriyet dönemi Kütahya çinisinde görülen uygulama teknikleri ve yenilikler, Yüksek Lisans Tezi, Afyon Kocatepe Üniversitesi, Sosyal 
Bilimler Enstitüsü, Seramik Anasanat Dalı, Afyonkarahisar, 72.

Kubbe-i Hadra Bilim Kurulu Kararları, 2020, I. ve II. Kurul Kararı, Mevlana Müze Müdürlüğü, Konya.

Küçükdağ Y., 1996, 1251 H/1835 M. Tarihli Mevlana Türbesi ve Çelebi Efendi Konağı Tamir ve İnşası Defteri, Türkiyat Araştırmaları Enstitüsü, Türkiyat Araştırmaları Dergisi, 2, 182-184.

Oğuzoğlu Y. ve Mülayim S., 1984, Konya Mevlana Türbesi'nin Restorasyonu ille ilgili H. 1109 (1698) Tarihli Üç Belge, Arkeoloji Sanat Tarihi Dergisi, 3, 115122.

Okyar F., 2005, The Technology of Frit Making in Iznik, 2005, Key Engineering Materials, 264-268, 23912394.

Önge Y., 1985, Mevlana Türbesi'nin Çini Tezyinatı, I. Milli Mevlana Kongresi Tebliğler, 401-408. Konya: Selçuk Üniversitesi.

Özönder H., 1988, Mevlana Türbe ve Külliyesinin Tamir ve İlaveler Kronolojisi, Selçuklu Üniversitesi Selçuk Dergisi, Selçuklu Araştırmaları Merkezi. 2, 23-29

Sevgili M., 2006, İznik'te Kullanım Amaçlı Üretilen (16.yy) Tabak ve Kase Formlarının Günümüzdeki Benzer Üretimleriyle Karşılaştırılması, Yüksek Lisans Tezi, Dokuz Eylül Üniversitesi, Güzel Sanatlar Enstitüsü, Geleneksel, İzmir, 89.

Şahin F., 1988, Cumhuriyet Dönemi Kütahya Çini ve Keramik Sanatı, İstanbul Sanat Tarihi Yıllığı XIII. 131 $-151$.

Yılmaz M., 2011, İznik Çinilerinde Nanopigment Kullanımı Ve Geleneksel Pigmentlerle Karşılaştırılması, Yüksek Lisans Tezi, Sakarya Üniversitesi Fen Bilimleri Enstitüsü, Sakarya, 235.

\section{internet kaynakları}

1- https://www.aksehirpostasi.com/mevlana-muzesindeki-yesil-kubbe-cinileri-restore-edilecek/25613/ (04.08.2020) 